\title{
Rabi cropped area forecasting of parts of Banaskatha District,Gujarat using MRS RISAT-1 SAR data
}

\author{
R.A.Parekh ${ }^{\mathrm{a},{ }^{*},}$ R.L.Mehta ${ }^{\mathrm{b}}$, A.Vyas ${ }^{\mathrm{c}}$ \\ a,, ${ }^{*}$ CCenter for Environmental Planning and Technology, Ahmedabad, India-rutuparekh02@gmail.com,anjanavyas@cept.ac.in \\ ${ }^{\mathrm{b}}$ Space Application Center, ISRO, Ahmedabad, India- rlmehta@sac.isro.gov.in
}

Commission VIII, WG VIII/8

KEY WORDS: Dual polarisations, multi-temporal, discrimination, cropped and un-cropped areas

\begin{abstract}
:
Radar sensors can be used for large-scale vegetation mapping and monitoring using backscatter coefficients in different polarisations and wavelength bands. Due to cloud and haze interference, optical images are not always available at all phonological stages important for crop discrimination. Moreover, in cloud prone areas, exclusively SAR approach would provide operational solution. This paper presents the results of classifying the cropped and non cropped areas using multi-temporal SAR images. Dual polarised C- band RISAT MRS (Medium Resolution ScanSAR mode) data were acquired on $9^{\text {th }}$ Dec. 2012, 28 $8^{\text {th }} J a n .2013$ and $22^{\text {nd }}$ Feb. 2013 at $18 \mathrm{~m}$ spatial resolution. Intensity images of two polarisations (HH, HV) were extracted and converted into backscattering coefficient images. Cross polarisation ratio (CPR) images and Radar fractional vegetation density index (RFDI) were created from the temporal data and integrated with the multi-temporal images. Signatures of cropped and un-cropped areas were used for maximum likelihood supervised classification. Separability in cropped and umcropped classes using different polarisation combinations and classification accuracy analysis was carried out. FCC (False Color Composite) prepared using best three SAR polarisations in the data set was compared with LISS-III (Linear Imaging Self-Scanning System-III) image. The acreage under rabi crops was estimated. The methodology developed was for rabi cropped area, due to availability of SAR data of rabi season. Though, the approach is more relevant for acreage estimation of kharif crops when frequent cloud cover condition prevails during monsoon season and optical sensors fail to deliver good quality images.
\end{abstract}

\section{INTRODUCTION}

The agricultural applications of remote sensing have been traditionally focused on the use of data from optical sensors. Cloud cover in Kharif season is main obstacle for optical remote sensing. SAR can penetrate through cloud cover. This phenomena is well known now that SAR image acquired on a cloudy day is as good as that taken in clear sun shine day. These constraints seriously impede the use of optical data for operational crop acreage estimates especially during Kharif season. Moreover, in cloud prone areas, exclusively Radar approach would provide operational solution. Unlike visible and infrared wavelengths which are sensitive primarily to plant biochemical properties, microwave energy respond to large scale structural attributes of vegetation i.e. the size, shape and orientation of the leaves, stems, and heads and its water composition.

Multi-temporal data is more suitable for crop monitoring as changes and variations in crop growth can be observed. Preliminary analysis of multi-temporal C-band SAR data for crops grown in India showed good results for rice crop identification (Premlatha and Rao, 1994, Patel et. al., 1995, Kurosuet al., 1995, Chakraborty and Panigrahy, 2000). Studies on multi-polarisation data indicated improved crop classification accuracy. Foody et al. (1994) classified crop type using all three linear polarisations $(\mathrm{HH}, \mathrm{VV}, \mathrm{HV})$ and several polarimetric parameters (the co-polarized and cross-polarized, pedestal height and variation coefficients). L-band has shown maximum separability for discrimination of vegetation/crop cover (Bhatt et al., 2007). In agriculture application, radar multi-frequency L-band and P-band can discriminate between sorghum and corn; and C-band can discriminate between bare soil and millet (Rosenthal et al., 1985). The integration of data from optical and SAR sensors generate a synergistic effect (Mcnairn et al., 2008). Present study has been carried out to assess the potential of muti-temporal C-band MRS RISAT SAR data for early forecasting of area under rabi crops.

\section{STUDY AREA}

Banaskatha is a district of Gujarat state, western India. The territory has an area of around 10,00,000 ha. (3.11\% of Gujarat's area), which is surrounded by Marwal and Sirohi regions of Rajasthan State in north, Sabarkatha district in the east, Mehsana district in the south and Patan district in the west. The district is situated between $23.33^{\circ}$ to $24.45^{\circ} \mathrm{N}$ latitude and $72.15^{\circ}$ to $73.87^{\circ} \mathrm{E}$ longitude (Fig. 1). The district includes the area around the bank of Banas River. The economy of district is mainly based on agriculture and food processing, textile and mineral based industry. The district is the third largest producer of oilseeds especially mustard seeds. Predominant crops grown in kharif season are bajra, greengram, sisamum, caster and cotton and in rabi season are Potato, Mustard, cumin and funnel.

\section{METHODOLOGY AND DATA USED}

Dual polarised C- band RISAT (MRS) data were acquired on $9^{\text {th }}$ Dec. 2012, $28^{\text {th }}$ Jan. 2013 and $22^{\text {nd }}$ Feb., 2013. Intensity images of two polarisations (HH, HV) were extracted and converted into backscattering coefficient images. From the images salt and pepper effect was removed and was smoothened using the Lee filter with $5 * 5$ kernal size in order to suppress the speckle effect. Computation of backscattering range was done using equation 1 : 


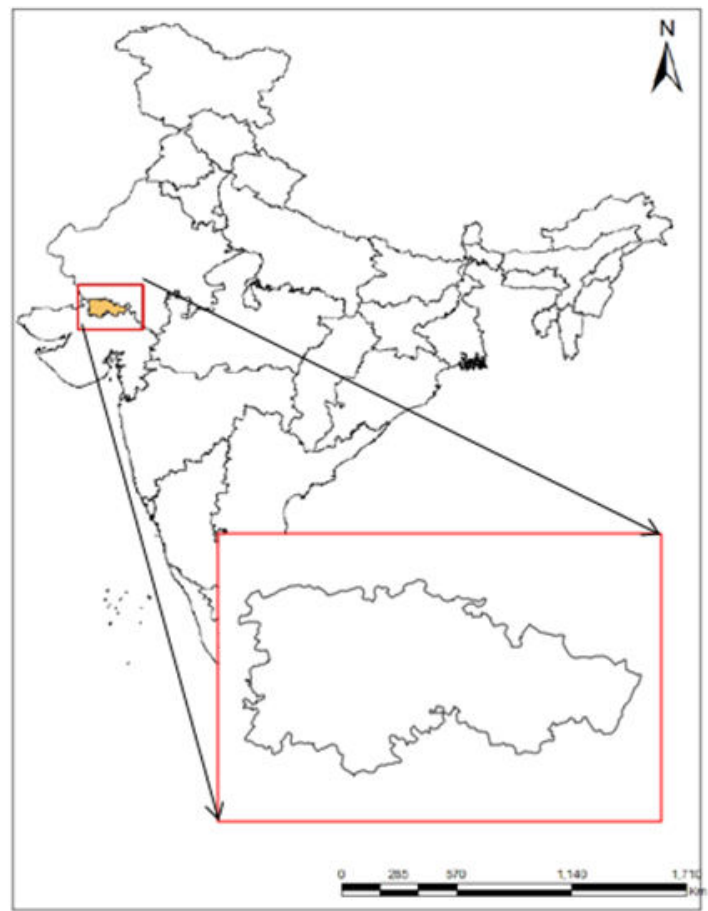

Figure 1 Illustrates part of study area (Banaskantha District, Gujarat, India)

(Boundry: http://bhuvan.nrsc.gov.in/gis/thematic/index.php)

$$
\sigma^{o}(d B)=20 * \log _{10}\left(\mathrm{DN}_{\mathrm{p}}\right)-\mathrm{K}_{\mathrm{dB}}+10 \log _{10}\left(\operatorname{Sin}\left(i_{p}\right) / \operatorname{Sin}\left(i_{\text {center }}\right)\right)
$$

Where, $\quad \sigma^{o}=$ radar backscatter coefficient in $\mathrm{dB}$ $\mathrm{DNp}=$ digital number or the image pixel graylevel count for the pixel $\mathrm{p}$ $\mathrm{K}_{\mathrm{dB}}=$ calibration constant in $\mathrm{dB}$ $i_{p}=$ incidence angle for the pixel position $\mathrm{p}$ (in degree) $i_{\text {center }}=$ incidence angle at the scene center (can be obtained from BAND_META.txt file)

CPR: $\sigma_{\mathrm{HV}}^{o} / \sigma_{\mathrm{HH}}^{o}$

RFDI: $\left(\sigma_{\mathrm{HH}}^{o}-\sigma_{\mathrm{HV}}^{o}\right) /\left(\sigma_{\mathrm{HH}}^{o}+\sigma_{\mathrm{HV}}^{o}\right)$

The cross polarisation ratio (CPR) images and radar fractional vegetation density index (RFDI) images were computed for all the three data set using equation 2 and 3 respectively. Three dates temporal dual polarisation images and the respective CPR and RFDI images were stacked to form an integrated image comprising of six multi-date polarisations and six derived polarisation images. The Training windows of cropped and uncropped areas were selected using the LISS-III image of the same area. Training signatures of seven land use classes i.e. urban areas, surface water bodies, mustard, potato, fallow/uncultivated land, river/dry sand and forested area were computed using ground truth information and SA images. Contribution of twelve different polarisation procured on three different dates for discrimination of cropped and un-cropped areas was evaluated using the Jefferies-Matusita signature separability and by computing classification accuracies. Cropped and un-cropped areas were classified using maximum likelihood classification technique.

\section{RESULTS AND DISCUSSION}

Radar backscattering from distributed target feature depends upon its geometrical properties and dielectric constant. Different features with varying geometrical and dielectrical properties produce different backscattering. This provides the ability to interpret features on radar images. The effect of SAR polarisation on backscattering by crops is also very important for discriminating cropped areas from the un-cropped areas. The vegetation tends to depolarise the SAR returns as the canopy cover increases. The combination of co-polarised and crosspolarised SAR images gives significant information about the cropped areas.

Rabi crops are grown from the month of November to March. The LISS-III of $22^{\text {nd }}$ January, 2013was used to compare the cropped areas estimated using SAR images. Potato, Mustard, cumin and funnel are the four main crops grown in rabi season. Mustard is sown in the middle of October just after the harvest of kharif crops. For rest of the rabi crops sowing operations are in progress in the month of November. During the time of SAR acquisition on $9^{\text {th }}$ Dec., 2012 the crop was in its early vegetative stage, while during $28^{\text {th }}$ Jan., 2013 crops were near to peak vegetative growth stage. Crops contribution towards the backscattering coefficient during peak growth stage was high, resulting in brighter image tone. Using the ground truth information it was observed that Mustard crop gives yellowish tone and potato crop appeared in pinkish tone on the SAR FCC. Fallow land observed in SAR and optical images also shows different color tone, in SAR images it appears as dark brown to black and same area appears to be dark green in optical image seen in Fig. 2a and 2b. The total cropped areas observed in SAR FCC matched very closely with the red tone of LISS-III image (Fig. 2a and 2b).

The separability measurement (Jeffries-Matusita) is used to quantify how well spectral classes can be separated from each

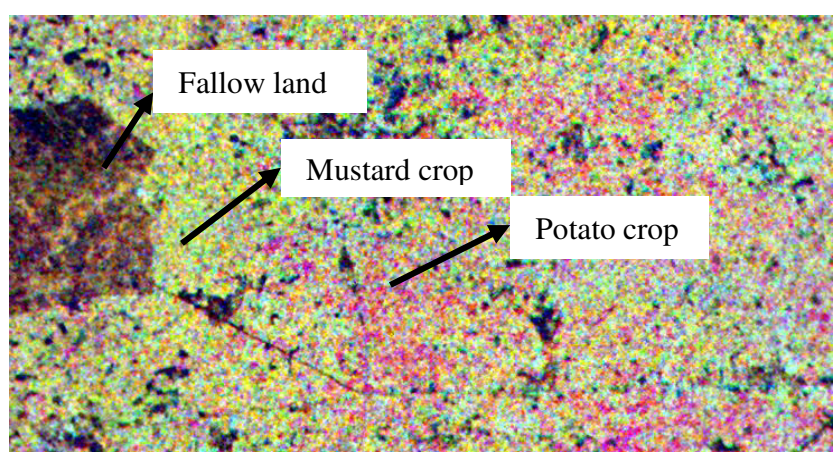

Figure 2a Multidate RISAT-1 FCC showing various crop signature (R: HV(28 ${ }^{\text {th }}$ January 2013), G:HV $\left(22^{\text {nd }}\right.$ February 2013),B:RFDI (28 ${ }^{\text {th }}$ January 2013))

other. A spectral class is associated with a probability density function. The Jeffries-Matusita is a measure of probability density functions between a pair of normally distributed classes associated with one band or several bands (Richards, 1986). The Jeffries-Matusita distance is generally utilized for bands selections which will result in maximum separability between different land use classes. The contribution of different 12 images integrated in the data set was determined using JeffriesMatusita separability algorithm. The best two polarisation 


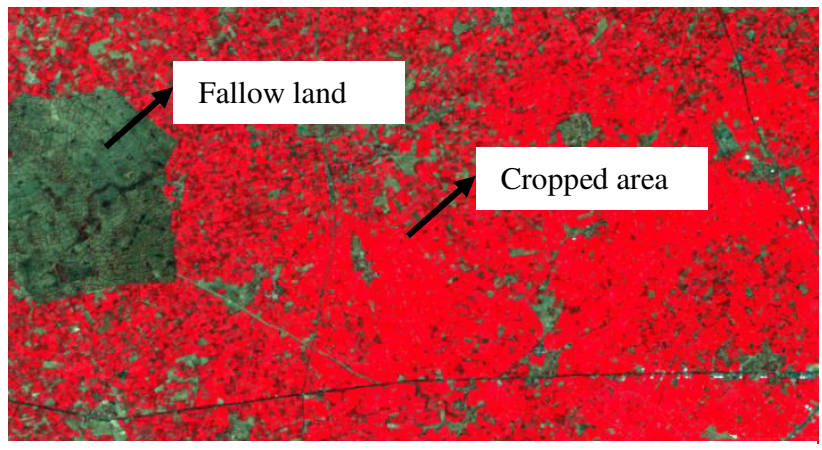

Figure 2b LISS III FCC showing cropped and uncropped area $\left(22^{\text {nd }}\right.$ January 2013$)$

discriminating the two classes (cropped and uncropped) were found to be the HV polarisation of $28^{\text {th }}$ Jan., 2013 and HV polarisation of 22nd Feb., 2013. This is due to the fact that on $28^{\text {th }}$ Jan., 2013 the crops were close to peak vegetation stage and $\mathrm{HV}$ polarisation accounts for the volume scattering causing a high backscatter, while on $22^{\text {nd }}$ Feb., 2013 date the crops are towards the maturity resulting in decrease in backscattering. This large difference in backscattering values between the two signatures resulted in high separability. The best three polarisation found were HV polarisation of $28^{\text {th }}$ Jan., 2013 and HH polarisation of $22^{\text {nd }}$ Feb., 2013 and RFDI of $28^{\text {th }}$ Jan., 2013. Best three polarizations images thus obtained were used to prepare the RISAT-1 FCC used for comparison with LISS III FCC image. It is noteworthy to find that RFDI and ratio contributed more towards separability as compared to $9^{\text {th }}$ Dec., 2012 image. The integrated image comprising of 12 layers was classified using maximum likelihood classification (available in ENVI software) to cropped and uncropped classes. Maximum likelihood classification assumes that the statistics for each class in each band are normally distributed and calculates the probability that a given pixel belongs to a specific class. ENVI implements maximum likelihood classification by calculating the following (equation 4) discriminant functions for each pixel in the image (Richards, 1999).

$$
\mathrm{g}_{\mathrm{i}}(\mathbf{x})=\ln p\left(\omega_{i}\right)-1 / 2 \ln \left|\sum_{i}\right|-1 / 2\left(x-m_{i}\right)^{T} \sum_{i}^{-1}\left(x-m_{i}\right)
$$

Where, $\mathrm{i}=$ class

$\mathrm{x}=\mathrm{n}$-dimensional data (where $\mathrm{n}$ is the number of bands)

$\mathrm{p}\left(\omega_{\mathrm{i}}\right)=$ probability that class $\omega_{\mathrm{i}}$ occurs in the image and is assumed the same for all classes $|\Sigma i|=$ determinant of the covariance matrix of the data in class $\omega_{i}$

$\Sigma_{\mathrm{i}}^{-1}=$ its inverse matrix

$\mathrm{m}_{\mathrm{i}}=$ mean vector.

The classification accuracy of the three date dual polarisations images as well as derived layers (12 image layers) was done. Table 1 and 2 show the results. A high classification accuracy of $93.14 \%$ (table 1) was achieved. However, it is observed that the classification accuracy using only three date temporal data (table 2) was more or less same to that obtained using 12 layers. An area of 3,86,405 ha and 3,57,778 ha is classified as cropped area using SAR integrated image and LISS-III image, respectively.

\section{CONCLUSION}

The study is taken up to assess the potential of dual polarisation RISAT-1 SAR images for Rabi crop acreage estimation. Multitemporal SAR images were procured over the parts of Banaskatha district, Gujarat. Along with multi date SAR images the contribution of cross polarisation ratio images for separability between cropped and un-cropped areas were also assessed. Performance of SAR images was compared with the optical data. For the study purpose 12 image layers were used to check the performance of layers for distinguishing fallow and cropped areas. The images showing highest separability between cropped and fallow land were considered best for preparing FCC. This FCC helped us to visually compare with optical FCC between fallow and cropped areas.

\begin{tabular}{|c|c|c|c|}
\hline \multirow{2}{*}{$\begin{array}{l}\text { Classified } \\
\text { Classes }\end{array}$} & \multicolumn{2}{|c|}{ Reference Classes } & \multirow{2}{*}{$\begin{array}{l}\text { No. of } \\
\text { Pixels }\end{array}$} \\
\hline & $\begin{array}{c}\text { Cropped } \\
\text { areas }\end{array}$ & $\begin{array}{c}\text { Un-Cropped } \\
\text { areas }\end{array}$ & \\
\hline Cropped areas & 91.78 & 6.48 & 21374 \\
\hline Un-Cropped & 8.22 & 93.52 & 63665 \\
\hline No. of Pixels & 18595 & 66444 & 85039 \\
\hline
\end{tabular}

Table 1 Classification accuracy derived using three date temporal data integrated with CPR and RFID images

\begin{tabular}{|c|c|c|c|}
\hline \multirow{2}{*}{$\begin{array}{c}\text { Classified } \\
\text { Classes }\end{array}$} & \multicolumn{2}{|c|}{ Reference Classes } & \multirow{2}{*}{$\begin{array}{l}\text { No. of } \\
\text { Pixels }\end{array}$} \\
\hline & $\begin{array}{c}\text { Cropped } \\
\text { areas }\end{array}$ & $\begin{array}{c}\text { Un-Cropped } \\
\text { areas }\end{array}$ & \\
\hline Cropped areas & 92.98 & 4.59 & 20329 \\
\hline Un-Cropped & 7.02 & 95.41 & 64697 \\
\hline No. of Pixels & 18584 & 66442 & 85026 \\
\hline
\end{tabular}

Table 2 Classification accuracy derived using three date temporal data

- SAR FCC prepared using the best three polarisations/ derived layers (HV polarisation of $28^{\text {th }}$ Jan., 2013, HH of $22^{\text {th }}$ Feb., 2013 and RFDI image of $28^{\text {th }}$ Jan.,2013 matched closely with the LISS-III image of $22^{\text {nd }}$ Jan., 2013.

- SAR temporal data can be successfully used for the estimation of total cropped areas.

- Derived layers (CPR and RFDI) did not improved the classification accuracy in addition to three dates temporal dual polarisation SAR images, though these contributed more towards separability as compared to the initial stage crops image (9th Dec., 2012).

\section{ACKNOWLEDGMENT}

We express our gratitude to Shri. Kiran Kumar, the then Director, SAC (ISRO)for encouragement to carry out work on this topic. We are also thankful to Dr. M. Chakraborty, the then GD, ATDG, for his guidance and useful suggestions. 


\section{REFERENCES}

Aggarwal, I.K., Shyam Lata and Pandey.R.S., 2004 Agricultural Statistics at a Glance. Arihant Offset, Janakpuri, New Delhi110058 .

Bhatt, H., Golakiya, P., B.A. and Rajani, A.V., 2007. Identification of Groundnut Crop and Biomass Estimation using SAR data. Conference of Joint Experiment Project, Microwave Remote Sensing Data Utilisation. May 15-16, pp. 1.1-1.11.

Chakraborty, M., and Panigrahy, S., 2000. A processing and Software System for Rice Crop Inventory using Multidate Radarsat ScanSAR data. ISPRS Journal of Photogrammetry \& Remote Sensing, 55, pp.119-128.

Foody, G. M., McCulloch, M. B., and Yates, W. B., 1994. Crop Classification from C-band Polarimetric Radar data. International Journal of Remote Sensing, 15, 2871-2885.

Kurosu, T., Fujita, M., and Chiba, K., 1997. The identification of Rice Fields using Multi-temporal ERS-1 C band SAR data. International Journal of Remote Sensing, 18, pp.2953-2965.

McNairn, H., Champagne, C., Sang, J., Holmstorm, D., and Reichert, G., 2008. Integration of Optical and Synthetic Aperture Radar (SAR) imagery for Delivering Operational Annual Crop Inventories. ISPRS Journal of Photogrammetry \& Remote Sensing, 64(5), p.434449.doi:10.1016/j.isprsjprs.2008.07.006.

Premlatha, M. And Rao, P. P. N., 1994. Crop Acreage Estimation Using ERS-1 SAR Data. Journal of Indian Society of Remote Sensing, 22, 139-147.

Patel, N. K., Medhavy, T. T., Patnaik, C., and Hussain, A., 1995. Multi Temporal ERS-1 SAR Data for Identification of Rice Crop. Journal of Indian Society of Remote Sensing, 23, 33-39.

Richards, J.A., 1986. Remote Sensing Digital Image Analysis: An introduction, Germany: Springer.

Richards, J.A., 1999, Remote Sensing Digital Image Analysis, Springer-Verlag, Berlin, 240,

Rosenthal, W. D., Blanchard, B. J., and Banchrd, A. J., 1985. Visible/IR/microwave Agricultural Classification, Biomass and Plant Height Algorithms. IEEE Trans. Geosci. And Remote Sensing, 23,pp.84-90. 